\title{
A Systematic Review of Current Teleophthalmology Services in New Zealand Compared to the Four Comparable Countries of the United Kingdom, Australia, United States of America (USA) and Canada
}

\author{
Liam Walsh' \\ Sheng Chiong Hong' \\ Renoh Johnson Chalakkal (iD) 2,3 \\ Kelechi C Ogbuehi (iD ${ }^{4}$ \\ 'Department of Ophthalmology, \\ Southern District Health Board, Dunedin, \\ Otago, New Zealand; ${ }^{2}$ Research and \\ Development, oDocs Eye Care, Dunedin, \\ Otago, New Zealand; ${ }^{3}$ Electrical and \\ Computer Engineering, University of \\ Auckland, Auckland, New Zealand; \\ ${ }^{4}$ Department of Medicine, University of \\ Otago, Dunedin, Otago, New Zealand
}

Correspondence: Renoh Johnson Chalakkal Email renohcj@odocs-tech.com
Background: Over 700,000 New Zealanders (NZ), particularly elderly and Māori, live without timely access to specialist ophthalmology services. Teleophthalmology is a widely recognised tool that can assist in overcoming resource and distance barriers. Teleophthalmology gained unprecedented traction in NZ during the COVID-19 pandemic and subsequent lockdown. However, its provision is still limited and there are equity issues. The aim of this study was to conduct a systematic review identifying, describing and contrasting teleophthalmology services in NZ with the comparable countries of Australia, USA, Canada and the United Kingdom.

Methods: The electronic databases Embase, PubMed, Web of Science, Google Scholar and Google were systemically searched using the keywords: telemedicine, ophthalmology, teleophthalmology/teleophthalmology. The searches were filtered to the countries above, with no time constraints. An integrative approach was used to synthesise findings.

Results: One hundred and thirty-two studies were identified describing 90 discrete teleophthalmology services. Articles spanned from 1997 to 2020. Models were categorised into general eye care $(n=21 ; 16 \%)$; emergency/trauma $(n=6 ; 4.5 \%)$; school screening $(n=25$; $19 \%)$; artificial intelligence (AI) $(\mathrm{n}=23 ; 18 \%)$; and disease-specific models of care (MOC) $(n=57 ; 43 \%)$. The most common diseases addressed were diabetic retinopathy $(n=23 ; 17 \%)$; retinopathy of prematurity $(n=9 ; 7 \%)$; and glaucoma $(n=8 ; 6 \%)$. Programs were mainly centred in the US $(n=72 ; 54.5 \%)$, followed by the UK $(n=29 ; 22 \%)$, then Canada $(n=16$; $12 \%)$, Australia $(\mathrm{n}=13 ; 10 \%)$, with the fewest identified in NZ $(\mathrm{n}=3 ; 2 \%)$. Models generally involved an ophthalmologist consultative service, remote supervision and triaging. Most models involved local clinicians transmitting fed-forward or live images.

Conclusion: Teleophthalmology will likely play a crucial role in the future of eye care. COVID-19 has offered a unique opportunity to observe the use of teleophthalmology services globally. Feed-forward and, increasingly, live-based teleophthalmology services have demonstrated feasibility and cost-effectiveness in similar countries internationally. New Zealand's teleophthalmology services, however, are currently limited. Investing in strategic partnerships and technology at a national level can advance health equities in ophthalmic care.

Keywords: teleophthalmology, telemedicine, videoconferencing, triaging, age-related macular degeneration, diabetic retinopathy 


\section{Introduction}

The Royal Australian and New Zealand College of Ophthalmology (RANZCO) defines teleophthalmology as information technology systems to deliver eye health care remotely using telecommunications services. It can be as basic as a telephone conversation or as complex as synchronous live videoconferencing. ${ }^{1}$

Seven hundred thousand (16\%) of New Zealanders live without timely access to healthcare services. New Zealand is characterised by mountainous terrain, long travel distances with a relatively small and geographically dispersed population of 4.92 million. $^{2}$ Indigenous Māori, New Zealand Europeans, and the elderly are over-represented in the central North, and lower South Islands. These are the areas with the poorest healthcare services and/or access to healthcare services, creating inequities. In NZ and comparable countries like the United Kingdom, most ophthalmologists (about 80\%) are concentrated in large metropolitan areas despite about $20 \%$ of the population living in regional and rural areas. ${ }^{2}$ There are only 169 ophthalmologists serving the entire NZ population. ${ }^{2}$

Many comparable English-speaking countries such as the UK also have significant rural and elderly populations which are often geographically isolated from already inadequately provisioned ophthalmology services. ${ }^{3}$

The United Kingdom (UK) has the fewest number of ophthalmologists $(2.3 / 100,000)$ in the European Union. The service in the UK is growing at a rate to meet only half of national eyecare demand by $2050 .^{3}$ The NZ association of salaried medical specialists also found NZ to have the lowest number $(3 / 100,000)$ of ophthalmologists amongst nine comparable countries. ${ }^{4}$ Australia (3.9/ 100,000), Canada (3.35/100,000) and USA (5.57/ $100,000)$ have higher numbers of ophthalmologists but are still predicted to have significant geographic and ethnic service deficits. ${ }^{5,6}$

RANZCO published teleophthalmology guidelines in 2020. They suggest that teleophthalmology is a possible alternative form of consultation (at a clinician's discretion) but that it does not replace in-person consultation. ${ }^{1}$

During the COVID19 pandemic, teleophthalmology has gained unprecedented traction. International "shelterin-place" orders, changes in reimbursement for telehealth services and international recommendations, by state and national organisations, to cancel non-urgent visits and procedures have been the main driving factors of teleophthalmology uptake. ${ }^{7}$ Virtual in-person consultations have become much more prevalent since lockdowns began around the world, adding to the pre-existing (mainly) store-forward teleophthalmology programmes. Telehealth remains the NZ Ministry of Health's (MOH) preferred model of care during 'Level 2' lockdown restrictions. ${ }^{8}$ Unfortunately, those most affected by COVID19 - low socio-economic, geographically isolated, indigenous or ethnic minority patients - tend to be the ones least able to benefit from teleophthalmology services due to equity barriers. ${ }^{7}$

The aim of this study was to conduct a systematic review identifying, describing and contrasting teleophthalmology services in NZ with the comparable countries of Australia, USA, Canada and the United Kingdom.

\section{Methods}

The electronic databases PubMed, Embase, Web of Science, Cochrane Library, Google Scholar and Google were systemically searched initially in August 2020 using the search terms (Telemedicine AND ophthalmology) OR tele-ophthalmology OR teleophthalmology AND (Australia OR United Kingdom OR United States OR America OR New Zealand OR Canada). Literature involving teleophthalmology in the countries listed above were reviewed. Exclusion criteria were, if the study was: a repeat study; not carried out in one of the specified countries; not involving teleophthalmology; not describing a specific program; not published in the English language; or published after August 2020 (Table 1).

The preferred reporting items for systematic reviews and meta-analysis (PRISMA) were conducted (Tables 1 and 2). Ethical approval was not required in accordance with Otago University and Southern DHB research guidelines. ${ }^{9}$

\section{Results}

One hundred and thirty-two studies were identified describing 90 discrete teleophthalmology services (Table 1). Articles spanned from 1997 to 2020. Models were categorised into general eye care $(\mathrm{n}=21 ; 16 \%)$; emergency/trauma $(\mathrm{n}=6 ; 4.5 \%)$; school screening $(\mathrm{n}=25 ; 19 \%)$; artificial intelligence (AI) $(n=23 ; 18 \%)$; and diseasespecific models of care (MOC) $(\mathrm{n}=57 ; 43 \%)$. The most common diseases addressed were: Diabetic Retinopathy $(\mathrm{n}=23 ; 17 \%)$; Retinopathy of prematurity $(\mathrm{n}=9 ; 7 \%)$; and Glaucoma $(n=8 ; 6 \%)$. Programs were mainly centred in the US $(n=72 ; 54.5 \%)$, followed by the UK $(n=29 ; 22 \%)$, then Canada $(n=16 ; 12 \%)$, Australia $(n=13 ; 10 \%)$, with the 
Table I Preferred Reporting of Items for Systematic Reviews and Meta-Analysis (PRISMA)

\begin{tabular}{|c|c|c|c|c|c|c|}
\hline & PubMed & Embase & Web of Science & Cochrane Library & Google Scholar & Google \\
\hline Identification & 200 & 187 & 173 & 5 & 604 & 121,000 \\
\hline \multicolumn{7}{|l|}{ Screening } \\
\hline Repeats & 2 & 75 & 162 & 5 & 420 & 342 \\
\hline Not country studied & 13 & 23 & 6 & 0 & 53 & 0 \\
\hline Not-teleophthalmology & 8 & 9 & I & 0 & 14 & 0 \\
\hline Case Study & 0 & 2 & 0 & 0 & 0 & 0 \\
\hline Guidelines & 2 & 0 & 0 & 0 & 0 & 0 \\
\hline Not in English/no information & 0 & 1 & 1 & 0 & 4 & 0 \\
\hline Outside time period & 0 & 0 & 0 & 0 & 1 & 0 \\
\hline \multicolumn{7}{|l|}{ Eligibility } \\
\hline Not a model of care & 43 & 66 & 3 & 0 & 105 & 120,879 \\
\hline Included articles & 132 & 11 & 0 & 0 & 12 & 0 \\
\hline Total discrete models of care & 122 & 10 & 0 & 0 & 0 & 0 \\
\hline
\end{tabular}

Notes: Adapted from: Moher D, Liberati A, Tetzlaff J, Altman DG; PRISMA Group. Preferred reporting items for systematic reviews and meta-analyses: the PRISMA statement. Ann Intern Med. 2009;15I (4):264-269,W64. Copyright the authors. Creative Commons. ${ }^{137}$

fewest identified in NZ ( $\mathrm{n}=3 ; 2 \%)$. Models generally involved an ophthalmologist consultative service, remote supervision and triaging. Most models involved local clinicians transmitting fed-forward or live images.

\section{General Eye Care}

Twenty-one studies involved general eye care. ${ }^{10-30}$ Nineteen of these studies centred around triaging services in the United Kingdom, USA and Australia.

Table 2 New Zealand's Discrete Teleophthalmology Services Evaluated Against Comparable Countries

\begin{tabular}{|l|l|l|l|l|l|}
\hline & NZ & Australia & UK & USA & Canada \\
\hline General Eye Care & 1 & 5 & 8 & 6 & 1 \\
\hline School Screening & 0 & 0 & 5 & 18 & 2 \\
\hline Emergency Eye Care & 0 & 3 & 2 & 1 & 0 \\
\hline $\begin{array}{l}\text { Disease-Specific } \\
\text { Models of Care } \\
\text { (MOC) }\end{array}$ & 2 & 5 & 11 & 26 & 13 \\
\hline $\begin{array}{l}\text { Artificial Intelligence } \\
\text { (Al) }\end{array}$ & 0 & 0 & 3 & 20 & 0 \\
\hline
\end{tabular}

Triaging services mainly involved a feed-forward mechanism where eye-related screening information: usually medical history; ocular images; visual acuity; and intraocular pressure were collected by a trained community member and evaluated remotely by an ophthalmologist. Trained community members often included general practitioners but also optometrists, hospital district medical officers, medical students, nurses and trained prison officers. This was then sent via email or centralised clinical program to a hospital-based Ophthalmology consultant for advice and triaging for potential specialist appointment. ${ }^{27}$ Most studies focussed on adults, whilst one Canadian study involved solely paediatric screening. ${ }^{26}$

Two programmes involved real-time virtual video consultations with Ophthalmologists. In Western Australia optometrists, hospital RMOs and GPs would undertake a history and exam via Skype-based guidance under an Ophthalmologist. Ophthalmologists in London, United Kingdom provided weekly live video advice to South African Ophthalmologists for 30 minutes, using fedforward retinal videos and video slit lamp recordings of patients shown at the meetings. ${ }^{26,29}$ 


\section{School Screening}

Twenty-five studies were identified. One Canadian study involved teleophthalmology for remotely testing Visual Acuity while the rest focussed on screening for amblyopia.

\section{Visual Acuity (VA)}

The single Canadian study on visual acuity screening in children was via a GoCheck phone application involving rotating a letter to match three others in a row. The application was administered by parents after 40 minutes of training in a supervised facility. There was no statistically significant difference in VA results compared to standard chart visual acuity testing ( $83 \%$ within one line) ${ }^{31}$

\section{Amblyopia}

Amblyopia is defined as decreased visual acuity without corresponding structural ocular disorders, but with a history of amblyogenic factors occurring at critical stages of vision development. There are multiple causes such as asymmetrically defocused images (eg, anisometropia), visual stimulus deprivation (eg, infantile cataracts), or misaligned eye images (eg, constant strabismus), and correction is age dependent. Traditional vision screening in children less than 3 years of age can be difficult due to poor child co-operation during the traditional exam (visual acuity, cover test, refraction, Hirschberg test, Bruckner reflex, etc). ${ }^{32}$

The American Association for Paediatric Ophthalmology and Strabismus (AAPOS) outlines criteria for strabismus or amblyopia detection. (1) Anisometropia (spherical or cylindrical) $>1.5$ D. (2) Any manifest strabismus. (3) Hyperopia $>3.5 \mathrm{D}$ in any meridian. (4) Myopia magnitude $>3.0 \mathrm{D}$ in any meridian. (5) Any media opacity $>1 \mathrm{~mm}$ in size. (6) Astigmatism $>1.5 \mathrm{D}$ within $\pm 10^{\circ}$ of the $90^{\circ}$ or $180^{\circ}$ axes, or $>1.0 \mathrm{D}$ in an oblique axis. (7) Ptosis with $<1 \mathrm{~mm}$ margin reflex distance. Amblyopia devices vary in the number and degree of variables measured. ${ }^{32}$

Photoscreener devices centre around pupil size and shape analysis. This includes red reflex and corneal reflex symmetry. There is variability between devices as to how many AAPOS guidelines are measured and the referral threshold. Some device referral guidelines are set completely according to AAPOS criteria, some according to the manufacturers' guidelines, and some independently.

Twenty-four studies were identified from the USA (18), UK (5), and Canada (1). ${ }^{32-55}$
The earliest photoscreener is the MTI photoscreener on which four validation studies were found. ${ }^{34-37}$ MTI performed well in constant strabismus (95-100\% sensitivity), picking up all media opacities and anisometropia greater than 1.00 diopter (100\% sensitivity). ${ }^{34-37}$ However overall MTI relies heavily on observer interpretation, with varying detection in the amblyopic factors of myopia (sensitivity $89 \%$, specificity $48-76 \%$ ), hyperopia (sensitivity $20-80 \%$, specificity $88-96 \%$ ), astigmatism (sensitivity 46-77\%, specificity $79-89 \%)$, anisocoria (0-100\% sensitivity), and alternating or intermittent strabismus $\quad(23-50 \%$ sensitivity). ${ }^{34-37}$ The studies also used varying criteria to determine these values making conclusions on clinical validity difficult.

There were seven studies covering four Plusoptix photoscreener series devices. ${ }^{32,38-43,55}$ The Plusoptix device sensitivities and specificities were comparable to other available photoscreeners when screening for amblyopia or amblyopic risk factors overall. ${ }^{33,39-43,55}$ Plusoptix demonstrated a combined sensitivity between $73-97.9 \%$ and specificity $70-90 \%$ in combined screening of amblyopia risk factors. ${ }^{32,38-42,54}$ The plusoptix photoscreeners tended to significantly underestimate hyperopia although this did improve with cycloplegia. ${ }^{39,55}$

Three studies were found on the PowerRefractor I and II (Plusoptix). ${ }^{51-53}$ Depending on the amount and weighting of amblyopic criteria applied sensitivity ranged from $47 \%$ to $99 \%$, specificity $49-100 \%$. False negative up to $6.3 \%$, false positives up to $35 \%{ }^{52-54}$

Iscreen (Vision Inc, Cordova, TN; one study USA) $87 \%$ sensitivity, $76 \%$ specificity. It is a small hand-held photoscreener capturing an off-axis binocular single image that is transmitted electronically for analysis. ${ }^{45}$

The spot (PediaVision or Welch Allyn; four studies USA) $78-96 \%$ sensitivity; $59-90 \%$ specificity. It is a handheld monocular photoscreener capturing a binocular picture and measures binocular noncycloplegic refractive error, ocular alignment, pupil size, and pupil distance using the optical reflex. There are two software versions. ${ }^{32,46,45}$

Other devices are the PR1000 and PR2000 (Topcon; one study UK), ${ }^{48}$ VPR1 (Clement Clarke Ltd., Harlow, one study UK) ${ }^{49}$ and vision research Visiscreen OSS-C photoscreener (Vision research corporation; one study UK), ${ }^{50}$ SureSight (Welch Allyn; one study USA) ${ }^{50,51}$ showed similar diagnostic accuracy to existing devices especially when compared to the MTI but validity of 
their diagnostic utility in clinical settings currently limited.

\section{Emergency Eye Care}

Six programmes were identified. Three from Australia, two from the United Kingdom and one from the United States.

In Australia, all three programmes used video slit-lamp technology. ${ }^{20,56,57}$ In Queensland (1997/1998) patients presenting with eye emergencies to the Mount Isa Emergency Department were assessed by Emergency department staff via a slit-lamp simultaneous live video streamed to an ophthalmologist in the city of Townsville $900 \mathrm{~km}$ away. Patients referred for urgent assessment fell from 17 to 4 , and both patients and clinicians found the system acceptable. ${ }^{56}$

In Western Australia, the Lions Outback Foundation (2014) established a live-video consultation service between Carnarvon General practitioners, hospital medical officers, optometrists and a general ophthalmologist in Perth $900 \mathrm{~km}$ away. Costs per patient varied between AU $\$ 166.89$ and AU\$665.44 with a set-up cost of $\$ 13,340$. It became more financially viable than having a physical consultation when the program reached 128 patients per year. $^{57}$

A 2016 review $^{20}$ of the 2014 Western Australian teleophthalmology service demonstrated significant technical, logistical and funding barriers impeding widespread programme usage. Technical barriers included long setup periods, and difficulties with the operating systems and devices. Logistically, regional and rural staff experienced high turnovers and referrals often became limited due to the decreased availability of specialists and of staff having knowledge of the service. Financially inadequate or no compensation for the health professionals was the biggest barrier. Many of these barriers were addressed in the review, with uptake increasing over 3.5 times in Western Australia after an improved program was implemented. ${ }^{20}$

Two programmes were identified in the UK. ${ }^{58,59}$ In 2010, the Twyn hospital Emergency Department located rurally in Gwynedd, North Wales established a live video consultation service with Ophthalmology specialists located in Bronglais Hospital. Eye clinics are usually held only once every two weeks by Bronglais ophthalmology specialists in Gwynedd Hospital and therefore emergencies require transfer, over 1 hour through narrow, mountainous roads to Bronglais eye department. ${ }^{58}$
Ophthalmic presentations to Twyn Emergency Department are seen by a nurse on duty. Ophthalmic signs are visualised remotely through a Topcon SL-D7 Slit-lamp camera via a Polycom or NEC Videoconferencing Unit. A review found that the service reduced ambulance transfers. ${ }^{58}$

Live video slit-lamp consultation between NHS Forth Valley Consultants in the United Kingdom and three emergency departments in Glasgow was established in 2018. They received more than 80 video referrals, halving the need for a second appointment. 59

There was one program identified from the United States: a general photography email consultation for deployed military personnel in the Middle East in order to gain rapid access to specialist services. ${ }^{60}$

\section{Disease Specific Models of Care (MOCs) Glaucoma}

Eight studies involved glaucoma screening based in the United Kingdom (5), USA (2) and Canada (1). Eye staff, usually optometrists (although sometimes GPs or rural ophthalmologists) take a history from glaucoma suspects. Relevant glaucoma information is collected (Intraocular pressure, central corneal thickness, visual fields, fundus imaging and optical coherence tomography optic disc imaging) but relies on having significant and particular ocular equipment. Glaucoma screening information is then sent to an Ophthalmologist usually via email who gives the patient a glaucoma risk grading. The ophthalmologist will compile a report and create a plan based on the grading or seek further information via face-to-face consult. No programmes utilised live video consultations. ${ }^{61-68}$

A USA based teleophthalmology services reduced patient travel times by 61 hours on average and physician wait times by $30 \%$ in comparison with in-person examination. Teleophthalmology visits were over half an hour shorter compared with in-person visits and the cost was $\$ 872$ patient, $80 \%$ less than the in-person examination. ICER in teleophthalmology was \$47.60/QALY/patient compared with in-person screening and had a greater incremental effectiveness providing an additional 0.12 QALY/patient examination. ${ }^{69}$

However, the cost of Glaucoma-based teleophthalmology services is complicated by the fact that there is no single test that is highly sensitive and specific for glaucoma, and therefore it necessitates a significant initial investment in expensive ocular examination equipment. Uncertainty surrounds who will bear this cost, as the 
parties investing in the equipment may not be the ones benefitting from the savings. For example, the GP may pay for the equipment setup, but the savings incurred will be at the tertiary level due to less hospitalisations. Some programmes are demonstrating $90 \%$ or higher sensitivity of machine-only screening for glaucoma, an increasingly cheaper alternative to in-person screening. ${ }^{69}$

\section{Age-Related Macular Degeneration (ARMD)}

Seven articles describing five programmes, one based in Canada and four in the United States, were found. ${ }^{70-74}$

One Canadian and one USA study described ARMD teleophthalmology consultations. An ophthalmology technician took a patient history, intraocular pressure, colour fundus photography and macula optical coherence tomography. Information was sent electronically to a retinal specialist and the patient was asked to report to a treatment centre as required. ${ }^{70}$

Three USA studies focused on the ForeseeHome Device, which displays measures of 500 retinal data points covering the central $14^{\circ}$ of the macular visual field, with some dots slightly out of line.

One study demonstrated that ForeseeHome correctly detected indicators of neovascular AMD more than $80 \%$ of the time. ${ }^{71}$ Another study with 26 patients demonstrated a specificity of $91.4 \%$ (ForseeHome) compared to $85.7 \%$ for Amsler Grid $(\mathrm{P}<0.5)$ and a sensitivity of $88.4 \%$ versus $57.6 \%$ for the Amsler grid $(P<0.05) .{ }^{72} \mathrm{~A}$ third study demonstrated good sensitivity and specificity in discrimination between new choroidal neovascular membranes and intermediate ARMD ${ }^{73}$ There is a paucity in the literature on the cost-effectiveness of using teleophthalmology for the management of ARMD. ${ }^{74}$

\section{Diabetic Retinopathy}

Twenty-three studies were identified: 10 USA; 7 Canadian; 4 Australian; and 2 from the United Kingdom. ${ }^{75-97}$ Programmes were mainly store-forward and screening in nature, taken by nurses or technicians. Programmes involved mydriatic, non-mydriatic, and digital fundus photography. ${ }^{75-97}$

Usually, additional information such as visual acuity and medical history (including cardiovascular and diabetic status) was also collected. The information uploaded was assessed by either a trained GP, an ophthalmologist or retina specialist using the ETDRS grading system. In some programmes the GP would first assess and then this would be checked by an ophthalmologist. The most prominent program of this kind is the UK National Health Service (NHS) diabetic eye screening program (DESP) established in 2013. The DESP has reportedly screened over 2 million people (with 60,000 referrals) since its inception, Diabetic eye disease is now no longer the leading cause of blindness in UK. ${ }^{98}$

Several studies have suggested that mydriatic retinal imaging is equivalent or superior to ophthalmic examination in detecting diabetic retinal changes. Non-mydriatic methods increase the incidence of inadequate photos but are still considered feasible for clinical use. The use of photography has resulted in decreased referral rates to the specialist. GPs were generally positive about their role in DR screening. ${ }^{93,96,87}$

An ultra-widefield camera screening system was deployed via a mobile van, screening 2788 diabetic patients in the San Francisco area, identifying 27\% as having diabetic retinopathy. Of these $5 \%$ had proliferative diabetic retinopathy. ${ }^{99}$

DR screening every 3 years, irrespective of risk, was most likely to be cost-effective, while screening every 5 years for low-risk groups and every 2 years for high-risk groups was cost-effective. A USA review of DR teleophthalmology cost-effectiveness found the cost to be $\$ 16,500$ per QALY compared to $\$ 17,500$ for nonteleophthalmology methods. The study estimated a total saving of 2.97 million per federal agency with a return on investment between $53 \%$ and 15 times. However, annual screening was not as cost-effective. ${ }^{93}$ Cost-effectiveness is limited by the size of the diabetes patient population, baseline diabetic eye screening rates, billing and staffing models, and the proportion of patients enrolled in health insurance plans.

\section{Non-Diabetic Retinal Eye Disease}

Three studies were identified from the United Kingdom, Canada and USA. ${ }^{100-102}$ They involved community-based physicians or optometrists taking retinal photos (mydriatic and non-mydriatic) then feeding these forwards via a secure web server to an ophthalmologist. One study demonstrated that $48 \%$ of referrals electronically did not require face-to-face consultation. ${ }^{102}$ Another study demonstrated the ophthalmologist could generate timely triaging responses, all within 1 day. ${ }^{100}$ 


\section{Oculoplastics}

There were no specific programmes involving only oculoplastics. However, half of the Middle East military personnel referrals in the emergency service (mentioned in Emergency Eye Care) involved oculoplastics. This involved photo being sent via email to Ophthalmologists based in the United States. ${ }^{60}$

\section{Strabismus}

Three studies were identified. Firstly, strabismus cases were included in the ORBIS International Telemedicine programme. Ophthalmologists in 25 developing countries submitted uploaded patient information and images to a secure server where "teacher" ophthalmologists in the United States would also review the diagnosis and treatment. High concordance was achieved in diagnosis but not in treatment plan (50\% concordance). ${ }^{103}$

A Canadian and a UK study demonstrated similar diagnostic accuracy with technician operated medium bandwidth video compared with in-person consults in manifest strabismus. Latent strabismus and micromovements were difficult to diagnose, and higher bandwidths (384 kbits/s or higher) were preferred as they lessened the need for repeated examination. Remote consults were also limited to how still the patient could be. ${ }^{104,105}$

\section{Cataracts}

Two programmes relating to cataracts were identified. ${ }^{106,107}$

In the United Kingdom, post-procedure cataract patients had a virtual video slit-lamp consult from a community clinic with a hospital-based ophthalmologist. Results suggested that although about $1 / 3$ of patients were anxious about being involved in a virtual rather than real consult, only $4 \%$ found the experience unacceptable, with similar post-operative checks achievable. ${ }^{106}$

Catrax is a New Zealand cloud-based service which piloted in 2016. It offers community and hospital-based clinicians an online form outlining the criteria needed for cataract surgery, which can be filled out and instantly analysed, usually providing an instant outcome as to whether a patient qualifies or not for cataract surgery. Early analysis suggests that triaging waiting times have been cut down by 4 weeks, clinicians spent less time filling out the forms and make fewer mistakes, overall increasing satisfaction and efficiency. ${ }^{107}$

\section{Retinopathy of Prematurity (ROP)}

Fifteen studies (2 Canadian, 10 US, 1 Australian, 1 UK, 1 NZ) describing 14 ROP screening programmes were identified. ${ }^{108-122}$ Most studies involved NICU nurses and technicians using commercially available digital retinal cameras. Digital retinal cameras were usually wide-angle cameras - typically the RetCam (Clarity Medical Systems, Inc. Pleasanton, CA, USA) - which offers a 130-degree view and collaging imaging potential. Composite images are then stored on a CD and sent on to an ophthalmologist (store forward approach). Some narrow-angle cameras, typically with a 50-degree field (eg, NM-200D of NIDEK, Inc. Pleasanton, CA, USA) are also used as they tend to be more portable, less expensive and do not require direct cornea contact. Six of the fifteen studies ${ }^{117-122}$ identified demonstrated a pooled sensitivity of $0.46-0.97$ and specificity of $0.89-1.00$ with inter observer reliability of $0.67-$ 0.89 . No major complications of the procedure were identified. ${ }^{108}$

A New Zealand study in 2010 compared the digital retinal imaging of 108 premature infants to binocular indirect ophthalmoscopy in a quaternary NICU by ophthalmologists. Digital retinal imaging was assessed to be reliable and efficient in detecting infant treatment requiring RoP (sensitivity $100 \%$ and specificity $97.9 \%$ ). ${ }^{115}$

In terms of cost-effectiveness another study estimated the costs per QALY to be $\$ 3193$ compared with $\$ 5617$ for binocular indirect ophthalmoscopy. ${ }^{109}$ The use of digital retinal imaging has also been shown to be less stressful on premature infants. Screening for RoP using a digital retinal camera was associated with a significantly lower stressrelated response than that observed using the conventional technique. ${ }^{110}$

There are now increasing numbers of studies on the use of this technology by neonatal nurses and trained technicians instead of ophthalmologists. Townsville uses two trained NICU nurses to send digital fundus images online to a triaging ophthalmologist at the state capital $1500 \mathrm{~km}$ away. ${ }^{111}$ Neonatal nurses in the larger San Francisco Bay Area community screened for ROP with a sensitivity of $100 \%$ and specificity of $99.5 \%$ with no adverse outcomes. ${ }^{112}$

\section{Artificial Intelligence}

Artificial intelligence has been implemented classically in diseases with high incidence, retinal conditions (diabetic retinopathy, age-related macular degeneration, retinopathy 
of prematurity), glaucoma, congenital cataracts, and some studies with retinal vein occlusions.

Diabetic Retinopathy (DR) is a major health issue worldwide, requiring urgent technological screening programmes. Artificial intelligence models typically focus on the specific DR features of microaneurysm, haemorrhage, exudation, cotton-wool spot, and neovascularization detection. The typical process is that a computer is trained using several fundus images with labelled diagnostic lesions, building a database/model based on the pattern characteristics. A new image is subsequently fed into the computer and can be compared to the model and/or the patient's metadata to provide a judgement. ${ }^{123}$

There are variations on this model, some using feedforward neural networks, consisting of the accumulating recognised pathology such as aneurysms and microhaemorrhages to create a diagnostic grading. The sensitivity of detection and accuracy for proliferative diabetic retinopathy ranged from $75 \%$ to $91.7 \%$. Non-proliferative diabetic retinopathy ranged from $75 \%$ to $94.7 \%$. $^{124}$

AMD AI programmes have traditionally used fundus photos as input as it is cheaper than OCT examination. The AI then extracts features of early, intermediate and late AMD to categorise the degree of macular degeneration. However, OCT methods, where the AI program is trained to look for deviations in the normal patterns and curvatures of OCT retinal layers, is increasing, reaching sensitivities from $87 \%$ to $100 \%{ }^{125-127}$

Retinopathy of prematurity AI programmes typically just categorise fundus images into plus or non-plus disease according to the diagnostic criteria with a USA-based program Retinal Image multiScale Analysis (RISA) achieving a 95\% diagnostic accuracy. ${ }^{128}$

Retinal vein occlusion models have typically been difficult to create. Internationally image-based vote methods have been trialled, where the computer uses a finite set of learned hypotheses, assigning a probability vote to each one. No studies were identified from the countries reviewed. ${ }^{129}$

AI programmes to identify glaucoma usually involve the AI system analysing a combination of the cup disc ratio in fundus images, the visual field, and thickness of retinal nerve fibre as measured by an OCT scan. One study was identified from the United States which trained the AI firstly with retinal nerve fibre layer OCT images $(93.1 \%$ accuracy), OCT image quadrant comparison of arcuate nerve fibre damage ( $87.3 \%$ accuracy) then combined it with $10-2$ Visual Field testing $(66.7 \%$ to $87.3 \%$ accuracy). ${ }^{126,130}$
Cataracts and anterior chamber ocular disease are assessed typically through AI analysis of multiple slit lamp images. Nuclear cataract AI recognition has achieved 70\% similarity against clinical grading. Some studies have focussed also on paediatric cataracts with promising results. ${ }^{125,131}$

\section{Discussion}

The significant increases in Ophthalmology service demand in New Zealand, accompanied with geographical, financial, and cultural inequalities, often worsened by the COVID-19 pandemic, have accelerated teleophthalmology services.

This systematic review demonstrates the feasibility of screening, triage and emergency programmes over all countries surveyed for a broad range of conditions. However, across the world and particularly in New Zealand there is significant underdevelopment.

Most programmes were confined to small numbers of patients in the United Kingdom, USA and Canada. NZ has only one retinal and one cataract screening programme. There were only two (Canadian and Australian) programmes focussing on indigenous peoples, none in New Zealand.

Feed-forward programmes have been well established for many years, but live video and telephone consult programmes have been traditionally few in number. Teleophthalmology is mainly used in general eye care, screening and emergency cases. Live consults have significantly increased during the COVID-19 pandemic, but their efficacy is still being evaluated.

The need for teleophthalmology services was so great in 2020 that it forced the global expansion of services illprepared for widespread use. The inevitable expansion of teleophthalmology necessitates that we focus more resources and energies into its development. Teleophthalmology remains viable, and it is possibly the only realistic candidate in the foreseeable future for the treatment of patients requiring specialist eye care in pandemic conditions.

RANZCO teleophthalmology guidelines (2020) state that digital systems must be safe, secure, with appropriate medical recording. Technology systems should be within 3 years old and in high definition (HD), operating within existing district health board systems. ${ }^{1}$

RANZCO acknowledges that the national infrastructure is not optimised for equitable access to teleophthalmology services. ${ }^{1}$ Teleophthalmology service provision and its inequities continue to be primarily driven by 
factors outside healthcare, such as poverty, internet access and technology start-up costs. Lack of formal governmental regulation and support for ICT start-ups, poor health or technology literacy and clinician fear of malpractice liability or resistance to change continue to hinder its development both in NZ and internationally. ${ }^{132}$

RANZCO states they would be keen to explore further the use of teleophthalmology to improve health equity but stops short of providing a future framework. ${ }^{133}$ Improving internet infrastructure via community-led internet service subsidy or WIFI-hotspot programmes have been suggested, there could also be technology distribution through giving out smartphone or similar devices along with community technology training programmes.

Community medical centres (GP, optometrists, urgent care and Emergency Departments) could be provisioned with coordinators who educate on and provide digital health tools. Live video primary care-based examination in remote NZ locations, such as those successfully implemented in Australia and the UK would limit exposure to COVID-19, reduce number of health practitioner visits and should improve eye care access.

In 2020, Counties Manukau District Health Board had more than 14,250 people waiting to see an ophthalmologist many of these Māori, Pacific and elderly. ${ }^{134}$ Home monitoring of conditions disproportionately affecting these groups such with portable DR screening, ForseeHOME (ARMD) and glaucoma (home-iCare) offer potentially more continuous long-term monitoring data, with less practitioner visits and COVID risk.

The existing model of DHB DR screening is resource intensive, requiring a team of trained clinicians to read the photographs. They also have high capital setup costs. National attendance at screening usually falls below recommended rates, particularly for Māori, Pacific and remote communities. ${ }^{135}$ Artificial intelligence technology offers ever improving methods to analyse fundus images faster, with greater accuracy and at lower cost than clinicians or technicians.

It has been difficult to quantify financial feasibility. Costs are usually incurred by front-line medical services such as GPs and optometrists, but savings are more at a global level in decreased hospital presentations and improved quality of life. UK studies particularly have shown reduction in hospital service costs; associated with non-detected or missed diagnosed cases and an improvement in quality-adjusted life years (QALY). The covering of this cost should be multidisciplinary involving the health sector. ${ }^{136}$
In conclusion, teleophthalmology will play a crucial role in the future of eye care. COVID-19 offers a unique opportunity for improvement and expansion. Feed-forward and increasingly live-based teleophthalmology services have demonstrated feasibility and cost-effectiveness in similar countries internationally. New Zealand's teleophthalmology services however are currently limited. Investing in strategic community technology partnerships nationally can help address health inequities in ophthalmic care. ${ }^{137}$

\section{Disclosure}

Dr Renoh Johnson Chalakkal reports grants from Health Research Council, New Zealand (Health Delivery Research Activation Grant 2020, 20/1176 Teleophthalmology in New Zealand) and oDocs Eye Care, for the conduct of the study. Dr Sheng Chiong Hong reports grants from Health Research Council, during the conduct of the study; non-financial support from oDocs Eye Care, outside the submitted work. The authors report no other potential conflicts of interest for this work.

\section{References}

1. RANZCO. RANZCO position statement - teleophthalmology in New Zealand; 2021. Available from: https://ranzco.edu/policies and_guideli/ranzco-position-statement-teleophthalmology-in-new -zealand/. Accessed May 17, 2021.

2. ASMS. Forecasting New Zealand's future medical specialist workforce needs; 2019. https://www.asms.org.nz/wp-content /uploads/2019/06/Research-Brief-specialist-workforceprojections-_172060.2.pdf. Accessed May 17, 2021.

3. NHS. Ophthalmology - the hospital eye service in crisis; 2018. Available from: https:/www.rcophth.ac.uk/wp-content/uploads/ 2019/01/RCOphth-A4-Census-Infographic.pdf. Accessed May 17, 2021.

4. ASMS. Assessing the extent of senior medical officer workforce shortages. ASMS, Toi Mata Hauora; 2019. Available from: https://books.google.co.nz/books?id=cQoSzgEACAAJ. Accessed August 23, 2021.

5. Bellan L, Buske L, Wang S, Buys YM. The landscape of ophthalmologists in Canada: present and future. Can J Ophthalmol. 2013;48(3):160-166. doi:10.1016/j.jcjo.2013.01.017

6. American Academy of Ophthalmology. The ophthalmology workforce - American Academy of Ophthalmology; 2020. Available from: https://www.aao.org/eyenet/article/theophthalmology-workforce. Accessed May 17, 2021.

7. Scanzera AC, Kim SJ, Paul Chan RV. Teleophthalmology and the digital divide: inequities highlighted by the COVID-19 pandemic. Eye (Basingstoke). 2021;35(6):1529-1531. doi:10.1038/s41433-02001323-x

8. Bradley S. The rise of teleoptometry - eyeonoptics; 2021. Available from: http://nzoptics.co.nz/articles/archive/the-rise-ofteleoptometry/. Accessed July 5, 2021.

9. Human Ethics Committees. University of Otago Council. Available from: https://www.otago.ac.nz/council/committees/com mittees/HumanEthicsCommittees.html.

10. Johnson KA, Meyer J, Yazar S, Turner AW. Real-time teleophthalmology in rural Western Australia. Aust J Rural Health. 2015;23(3):142-149. doi:10.1111/AJR.12150 
11. Ng M, Nathoo N, Rudnisky CJ, Tennant MTS. Improving access to eye care: teleophthalmology in Alberta, Canada. $J$ Diabetes Sci Technol. 2009;3(2):289. doi:10.1177/ 193229680900300209

12. Labiris G, Petounis A, Kitsos G, Aspiotis M, Psillas K. Internetbased counselling of remote ophthalmological patients. Acta Ophthalmolog Scandinav. 2003;81(1):86-88. doi:10.1034/ J.1600-0420.2003.00028_8.X

13. Barry CJ, Henderson C, Kanagasingam Y, Constable IJ. Working toward a portable tele-ophthalmic system for use in maximum-security prisons: a pilot study. Telemed $J$ e-Health. 2001;7(3):261-265. doi:10.1089/153056201316970966

14. BenZion I, Helveston EM. Use of telemedicine to assist ophthalmologists in developing countries for the diagnosis and management of four categories of ophthalmic pathology. Clin Ophthalmol (Auckland, NZ). 2007;1(4):489.

15. Borooah S, Grant B, Blaikie A, et al. Using electronic referral with digital imaging between primary and secondary ophthalmic services: a long term prospective analysis of regional service redesign. Eye. 2013;27(3):392. doi:10.1038/ EYE.2012.278

16. Cameron JR, Ahmed S, Curry P, Forrest G, Sanders R. Impact of direct electronic optometric referral with ocular imaging to a hospital eye service. Eye (London, England). 2009;23 (5):1134-1140. doi:10.1038/EYE.2008.196

17. Kennedy C, Bowman R, Fariza N, Ackuaku E, Ntim-Amponsah C, Murdoch I. Audit of Web-based telemedicine in ophthalmology. J Telemed Telecare. 2006;12(2):88-91. doi:10.1258/135763306776084356

18. Khan AA, Mustafa MZ, Sanders R. Improving patient access to prevent sight loss: ophthalmic electronic referrals and communication (Scotland). Public Health. 2015;129(2):117-123. doi:10.1016/J.PUHE.2014.10.010

19. Kumar S, Tay-Kearney M-L, Constable IJ, Yogesan K. Internet based ophthalmology service: impact assessment. $\mathrm{Br}$ J Ophthalmol. 2005;89(10):1382. doi:10.1136/BJO.2005.072579

20. O'day R, Smith C, Muir J, Turner A. Optometric use of a teleophthalmology service in rural Western Australia: comparison of two prospective audits. Clin Experiment Optomet. 2016;99(2):163-167. doi:10.1111/CXO.12334

21. Shahid K, Kolomeyer AM, Nayak NV. Ocular telehealth screenings in an urban community. Telemed $J$ e-Health. 2012;18 (2):95-100. doi:10.1089/TMJ.2011.0067

22. Yogesan K, Henderson C, Barry CJ, Constable IJ. Online eye care in prisons in Western Australia. J Telemed Telecare. 2001;7(Suppl 2):63-64. doi:10.1258/1357633011937173

23. Host BK, Turner AW, Muir J. Real-time teleophthalmology video consultation: an analysis of patient satisfaction in rural Western Australia. Clin Experiment Optomet. 2018;101(1):129-134. doi:10.1111/CXO.12535

24. Maa AY, Wojciechowski B, Hunt KJ. Early experience with Technology-Based Eye Care Services (TECS): a novel ophthalmologic telemedicine initiative. Ophthalmology. 2017;124 (4):539-546. doi:10.1016/J.OPHTHA.2016.11.037

25. Kennedy C, Van Heerden A, Cook C, Murdoch I. Utilization and practical aspects of tele-ophthalmology between South Africa and the UK. J Telemed Telecare. 2001;7(Suppl 1):20-22. doi:10.1177/ 1357633X010070S108

26. Areaux RG, de Alba Campomanes AG, Indaram M, Shah AS. Your eye doctor will virtually see you now: synchronous patient-to-provider virtual visits in pediatric tele-ophthalmology. $J$ AAPOS. 2020;24(4):197-203. doi:10.1016/j.jaapos.2020.06.004

27. Blackwell NA, Kelly GJ, Lenton LM. Telemedicine ophthalmology consultation in remote Queensland. The Medical Journal of Australia. 1997;167(11-12):583-586. doi:10.5694/j.13265377.1997.tb138904.x
28. Sheng Chiong BCH, Bao HM. SMARTPHONE FUNDUS IMAGING 1 smartphone fundus imaging; 2020. Available from: https://ourarchive.otago.ac.nz/handle/10523/10247. Accessed May 17, 2021.

29. Kurji K, Kiage D, Rudnisky CJ, Damji KF. Improving diabetic retinopathy screening in Africa: patient satisfaction with teleophthalmology versus ophthalmologist-based screening. Middle East Afr J Ophthalmol. 2013;20(1):56-60. doi:10.4103/09749233.106388

30. Matimba A, Woodward R, Tambo E, Ramsay M, Gwanzura L, Guramatunhu S. Tele-ophthalmology: opportunities for improving diabetes eye care in resource- and specialist-limited Sub-Saharan African countries. J Telemed Telecare. 2016;22 (5):311-316. doi:10.1177/1357633X15604083

31. Silverstein E, Williams JS, Brown JR, Bylykbashi E, Stinnett SS. Teleophthalmology: evaluation of phone-based visual acuity in a pediatric population. Am J Ophthalmol. 2021;221:199-206. doi:10.1016/j.ajo.2020.08.007

32. Crescioni M, Miller JM, Harvey EM. Accuracy of the Spot and Plusoptix photoscreeners for detection of astigmatism. J AAPOS. 2015;19(5):435-440. doi:10.1016/j.jaapos.2015.07.284

33. Kane S, Nguyen T. Off-axis photoscreening: A critical review of the literature [theses]. College of Optometry, Pacific University; 2001; Available from: https://core.ac.uk/download/pdf/ 212801425.pdf. Accessed September 24, 2021.

34. Berry BE, Simons BD, Siatkowski RM, Schiffman JC. Preschool vision screening using the MTI-photoscreener. Pediatr Nurs. 2001;27(1):27.

35. National Children's Eye Care Foundation Vision Screening Study Group. Screening for amblyopia in preverbal children with photoscreening photographs. Ophthalmology. 1998;105(5):856-863. doi:10.1016/S0161-6420(98)95026-6.

36. Simons BD, Siatkowski RM, Schiffman JC, Berry BE, Flynn JT. Pediatric photoscreening for strabismus and refractive errors in a high-risk population. Ophthalmology. 1999;106(6):1073-1080. doi:10.1016/S0161-6420(99)90243-9

37. Hatch SW, Tibbles CD, Mestito IR, Read R, Traveis L, Richman J. Validity and reliability of the MTI photoscreener. Optometr Vision Sci. 1997;74(10):859-864. doi:10.1097/ 00006324-199710000-00025

38. Freedman HL, Preston KL. Polaroid photoscreening for amblyogenic factors. An improved methodology. Ophthalmology. 1992;99(12):1785-1795. doi:10.1016/S0161-6420(92)31722-1

39. Matta NS, Arnold RW, Singman EL, Silbert DI. Comparison between the plusoptiX and MTI photoscreeners. Arch Ophthalmol. 2009;127 (12):1591-1595. doi:10.1001/archophthalmol.2009.294

40. Matta NS, Singman EL, Silbert DI. Performance of the Plusoptix vision screener for the detection of amblyopia risk factors in children. $J$ AAPOS. 2008;12(5):490-492. doi:10.1016/j. jaapos.2008.04.004

41. Matta NS, Singman EL, Silbert DI. Performance of the plusoptiX S04 photoscreener for the detection of amblyopia risk factors in children aged 3 to 5. J AAPOS. 2010;14(2):147-149. doi:10.1016/ j.jaapos.2010.01.006

42. Arthur BW, Riyaz R, Rodriguez S, Wong J. Field testing of the plusoptiX S04 photoscreener. J AAPOS. 2009;13(1):51-57. doi:10.1016/j.jaapos.2008.08.016

43. Dahlmann-Noor AH, Vrotsou K, Kostakis V, et al. Vision screening in children by Plusoptix Vision Screener compared with gold-standard orthoptic assessment. Br J Ophthalmol. 2009;93 (3):342-345. doi:10.1136/bjo.2008.138115

44. Kirk S, Diane Armitage M, Dunn S, Arnold RW. Calibration and validation of the 2 WIN photoscreener compared to the PlusoptiX S12 and the SPOT. J Pediatr Ophthalmol Strabismus. 2014;51 (5):289-292. doi:10.3928/01913913-20140701-01 
45. Silbert DI, Arnold RW, Matta NS. Comparison of the iScreen and the MTI photoscreeners for the detection of amblyopia risk factors in children. $J$ AAPOS. 2013;17(1):34-37. doi:10.1016/j. jaapos.2012.09.015

46. Peterseim MMW, Papa CE, Wilson ME, et al. The effectiveness of the Spot Vision Screener in detecting amblyopia risk factors. J AAPOS. 2014;18(6):539-542. doi:10.1016/j.jaapos.2014.07.176

47. Garry GA, Donahue SP. Validation of Spot screening device for amblyopia risk factors. $J$ AAPOS. 2014;18(5):476-480. doi:10.1016/j.jaapos.2014.07.156

48. Williams C, Lumb R, Harvey I, Sparrow JM. Screening for refractive errors with the Topcon PR2000 pediatric refractometer. Invest Ophthalmol Vis Sci. 2000;41(5):1031-1037.

49. Anker S, Atkinson J, Braddick O, et al. Identification of infants with significant refractive error and strabismus in a population screening program using noncycloplegic videorefraction and orthoptic examination. Invest Ophthalmol Vis Sci. 2003;44 (2):497-504. doi:10.1167/iovs.02-0070

50. Yanovitch T, Wallace DK, Freedman SF, et al. The accuracy of photoscreening at detecting treatable ocular conditions in children with Down syndrome. $J$ AAPOS. 2010;14(6):472-477. doi:10.1016/j.jaapos.2010.09.016

51. Harvey EM, Dobson V, Miller JM, et al. Accuracy of the Welch Allyn SureSight for measurement of magnitude of astigmatism in 3- to 7-year-old children. J AAPOS. 2009;13(5):466-471. doi:10.1016/j.jaapos.2009.08.013

52. Hunt OA. Evaluation of the measurement of refractive error by the PowerRefractor: a remote, continuous and binocular measurement system of oculomotor function. Br J Ophthalmol. 2003;87 (12):1504-1508. doi:10.1136/BJO.87.12.1504

53. Wolffsohn JS, Hunt OA, Gilmartin B. Continuous measurement of accommodation in human factor applications. Ophthal Physiolog Ooptics. 2002;22(5):380-384. doi:10.1046/J.14751313.2002.00050.X

54. Vasudevan B, Ciuffreda KJ, Wang B. An objective technique to measure the depth-of-focus in free space. Graefes Archiv Clin Experiment Ophthalmol. 2006;244(8):930-937. doi:10.1007/ S00417-005-0174-5

55. Singman E, Matta N, Tian J, Brubaker A, Silbert D. A comparison of the PlusoptiX S04 and A09 photoscreeners. Strabismus. 2013;21(2):85-87. doi:10.3109/ 09273972.2013 .786735

56. Rosengren D, Blackwell N, Kelly G, Lenton L, Glastonbury J. The use of telemedicine to treat ophthalmological emergencies in rural Australia. J Telemed Telecare. 1998;4(SUPPL. 1):97-99. doi:10.1258/1357633981931650

57. Raghavan K, Kumar S. Teleophthalmology: feasibility study in Western Australia. 2006

58. Kulshrestha M, Kelly S, Mahmood U. Teleophthalmology in practice. In: Graschew G, Rakowsky S, editors. Telemedicine Techniques and Applications. IntechOpen; 2011. Available from: https:/www.intechopen.com/chapters/16892. doi:10.5772/18175

59. Ives J. New virtual emergency consultation program for eye patients speeds up treatment times; 2021. Available from: https:/www.news-medical.net/news/20190807/New-virtualemergency-consultation-program-for-eye-patients-speeds-uptreatment-times.aspx. Accessed May 17, 2021.

60. Gensheimer WG, Miller KE, Stowe J, Little J, Legault GL. Military teleophthalmology in Afghanistan using mobile phone application. JAMA Ophthalmol. 2020;138(10):1053-1060. doi:10.1001/jamaophthalmol.2020.3090

61. Keenan J, Shahid H, Bourne RR, White AJ, Martin KR. Cambridge community optometry glaucoma scheme. Clin Experiment Ophthalmol. 2015;43(3):221-227. doi:10.1111/ ceo. 12398
62. Wright HR, Diamond JP. Service innovation in glaucoma management: using a web-based electronic patient record to facilitate virtual specialist supervision of a shared care glaucoma programme. Br J Ophthalmol. 2015;99(3):313-317. doi:10.1136/ bjophthalmol-2014-305588

63. Kassam F, Amin S, Sogbesan E, Damji KF. The use of teleglaucoma at the University of Alberta. J Telemed Telecare. 2012;18 (7):367-373. doi:10.1258/jtt.2012.120313

64. Kassam F, Yogesan K, Sogbesan E, Pasquale LR, Damji KF. Teleglaucoma: improving access and efficiency for glaucoma care. Middle East Afr J Ophthalmol. 2013;20:142-149. doi:10.4103/0974-9233.110619

65. Verma S, Arora S, Kassam F, Edwards MC, Damji KF. Northern Alberta remote teleglaucoma program: clinical outcomes and patient disposition. Can J Ophthalmol. 2014;49(2):135-140. doi:10.1016/j.jcjo.2013.11.005

66. Tuulonen A, Ohinmaa A, Alanko HI, Hyytinen P, Juutinen A, Toppinen E. The application of teleophthalmology in examining patients with glaucoma: a pilot study. J Glaucoma. 1999;8 (6):367-373. doi:10.1097/00061198-199912000-00005

67. Roberts HW, Rughani K, Syam P, Dhingra S, Ramirez-Florez S. The Peterborough scheme for community specialist optometrists in glaucoma: results of 4 years of a two-tiered community-based assessment and follow-up service. Curr Eye Res. 2015;40 (7):690-696. doi:10.3109/02713683.2014.957326

68. Trikha S, MacGregor C, Jeffery M, Kirwan J. The Portsmouth-based glaucoma refinement scheme: a role for virtual clinics in the future. Eye (Basingstoke). 2012;26(10):1288-1294. doi:10.1038/eye.2012.120

69. Thomas S, Hodge W, Malvankar-Mehta M, Bhattacharya S. The cost-effectiveness analysis of teleglaucoma screening device. PLoS One. 2015;10(9):e0137913. doi:10.1371/journal.pone.0137913

70. Brady CJ, Garg S. Telemedicine for age-related macular degeneration. Telemed e-Health. 2020;26(4):565-568. doi:10.1089/tmj.2020.0011

71. Loewenstein A, Ferencz JR, Lang Y, et al. Toward earlier detection of choroidal neovascularization secondary to age-related macular degeneration: multicenter evaluation of a preferential hyperacuity perimeter designed as a home device. Retina. 2010;30(7):1058-1064. doi:10.1097/IAE.0b013e3181d1a75e

72. Bressler NM, Meditec CZ. Preferential hyperacuity perimeter (PreView PHP) for detecting choroidal neovascularization study. Ophthalmology. 2005;112(10):1758-1765. doi:10.1016/j. ophtha.2005.06.008

73. Loewenstein A, Ferencz JR, Yeshurun I. et al. Comparison between the ForeseeHome perimeter and the Amsler grid, in patients with age related macular degeneration. In: Poster Presented at: The American Society of Retina Specialists Annual Meeting; 2008.

74. Sreelatha OK, Ramesh SVS. Teleophthalmology: improving patient outcomes? Clin Ophthalmol. 2016;10:285-295. doi:10.2147/OPTH.S80487

75. Boucher MC, Desroches G, Garcia-Salinas R, et al. Teleophthalmology screening for diabetic retinopathy through mobile imaging units within Canada. Can $J$ Ophthalmol. 2008;43(6):658-668. doi:10.3129/i08-120

76. Kim J, Driver DD. Teleophthalmology for first nations clients at risk of diabetic retinopathy: A mixed methods evaluation. JMIR Med Inform. 2015;3(1):e10. doi:10.2196/medinform.3872

77. Nathoo N, Ng M, Rudnisky CJ, et al. The prevalence of diabetic retinopathy as identified by teleophthalmology in rural Alberta. Can J Ophthalmol. 2010;45(1):28-32. doi:10.3129/i09-220

78. Carroll M, Cullen T, Ferguson S, Hogge N, Morton M, Kokesh J. Innovation in Indian healthcare: using health information technology to achieve health equity for American Indian and Alaska Native populations. Perspect Health Inf Manag. 2011;8(Winter):1d 
79. Chasan JE, Delaune B, Maa AY, Lynch MG. Effect of a teleretinal screening program on eye care use and resources. JAMA Ophthalmol. 2014;132(9):1045-1051. doi:10.1001/jamaophthalmol.2014.1051

80. Askew D, Schluter PJ, Spurling G, et al. Diabetic retinopathy screening in general practice: A pilot study. Aust Fam Physician. 2009;38(8):650-656

81. Yogesan K, Constable IJ, Eikelboom RH, van Saarloos PP. Teleophthalmic screening using digital imaging devices. Aust $N Z \mathrm{~J}$ Ophthalmol. 1998;26 Suppl 1:S9-S11. doi:10.1111/j.14429071.1998.tb01385.x

82. Ting DS, Tay-Kearney ML, Constable I, Vignarajan J, Kanagasingam Y. Retinal video recordings at different compression levels: a novel video-based imaging technology for diabetic retinopathy screening. Eye (Lond). 2013;27(7):848-853. doi:10.1038/eye.2013.53

83. Ting DS, Tay-Kearney ML, Vignarajan J, Kanagasingam Y. Diabetic retinopathy screening: can the viewing monitor influence the reading and grading outcomes. Eye (Lond). 2012;26 (12):1511-1516. doi:10.1038/eye.2012.180

84. Bursell SE, Fonda SJ, Lewis DG, Horton MB. Prevalence of diabetic retinopathy and diabetic macular edema in a primary care-based teleophthalmology program for American Indians and Alaskan Natives. PLoS One. 2018;13(6):e0198551. doi:10.1371/journal.pone.0198551

85. Murchison AP, Friedman DS, Gower EW, et al. A Multi-Center Diabetes Eye Screening Study in Community Settings: Study Design and Methodology. Ophthalmic Epidemiol. 2016;23 (2):109-115. doi:10.3109/09286586.2015.1099682

86. Chin EK, Ventura BV, See KY, Seibles J, Park SS. Nonmydriatic fundus photography for teleophthalmology diabetic retinopathy screening in rural and urban clinics. Telemed J E Health. 2014;20 (2):102-108. doi:10.1089/tmj.2013.0042

87. Liu Y, Rajamanickam VP, Parikh RS, et al. Diabetic Retinopathy Assessment Variability Among Eye Care Providers in an Urban Teleophthalmology Program. Telemed J E Health. 2019;25 (4):301-308. doi:10.1089/tmj.2018.0019

88. Kapoor R, Yuksel-Elgin C, Patel V, et al. Detecting Common Eye Diseases Using the First Teleophthalmology GlobeChek Kiosk in the United States: A Pilot Study. Asia. Pac J Ophthalmol (Phila). 2020;9(4):315-325. doi:10.1097/APO.0000000000000295

89. Kern C, Kortuem K, Hamilton R, Fasolo S, Cai Y, Balaskas K, Keane P, Sim D. Clinical Outcomes of a Hospital-Based Teleophthalmology Service: What Happens to Patients in a Virtual Clinic?. Ophthalmol Retina. 2019;3(5):422-428. doi:10.1016/j.oret.2019.01.011

90. Sharafeldin N, Kawaguchi A, Sundaram A, et al. Review of economic evaluations of teleophthalmology as a screening strategy for chronic eye disease in adults. Br J Ophthalmol. 2018;102 (11):1485-1491. doi:10.1136/bjophthalmol-2017-311452

91. Kanjee R, Dookeran RI, Mathen MK, Stockl FA, Leicht R. Sixyear prevalence and incidence of diabetic retinopathy and cost-effectiveness of tele-ophthalmology in Manitoba. Can J Ophthalmol. 2017;52:S15-S18. doi:10.1016/j.jcjo.2017.09.022

92. Kanjee R, Dookeran RI. Tele-ophthalmology for diabetic retinopathy in Canada - Meeting the needs of a growing epidemic. Can J Ophthalmol. 2016;51(3):133-134. doi:10.1016/j.jcjo.2016.04.004

93. Brady CJ, Villanti AC, Gupta OP, Graham MG, Sergott RC. Teleophthalmology screening for proliferative diabetic retinopathy in urban primary care offices: an economic analysis. Ophthalmic Surg Lasers Imaging Retina. 2014;45(6):556-561. doi:10.3928/ 23258160-20141118-11

94. Whited JD, Datta SK, Aiello LM, et al. A modeled economic analysis of a digital teleophthalmology system as used by three federal healthcare agencies for detecting proliferative diabetic retinopathy. Telemed $J$ e-Health. 2005;11(6):641-651. doi:10.1089/tmj.2005.11.641
95. Tennant MTS, Rudnisky CJ, Hinz BJ, MacDonald IM, Greve MDJ. Tele-ophthalmology via stereoscopic digital imaging: a pilot project. Diabetes Technol Ther. 2000;2(4):583-587. doi:10.1089/15209150050502005

96. Arora S, Kurji AK, Tennant MTS. Dismantling sociocultural barriers to eye care with tele-ophthalmology: lessons from an Alberta Cree community. Clin Investig Med. 2013;36(2):57. doi:10.25011/cim.v36i2.19567

97. Woodward MA, Ple-Plakon P, Blachley T, et al. Eye care providers' attitudes towards tele-ophthalmology. Telemed e-Health. 2015;21(4):271-273. doi:10.1089/tmj.2014.0115

98. Faes L, Fu DJ, Huemer J, et al. A virtual-clinic pathway for patients referred from a national diabetes eye screening programme reduces service demands whilst maintaining quality of care. Eye (Basingstoke). 2020;35:1-10. doi:10.1038/s41433-02001240-z.

99. Afshar AR, Oldenburg CE, Stewart JM. A novel hybrid fixed and mobile ultra-widefield imaging program for diabetic teleretinopathy screening. Ophthalmol Retina. 2019;3(7):576-579. doi:10.1016/j.oret.2019.03.007

100. Kelly SP, Wallwork I, Haider D, Qureshi K. Teleophthalmology with optical coherence tomography imaging in community optometry. Evaluation of a quality improvement for macular patients. Clin Ophthalmol (Auckland, NZ). 2011;5(1):1673-1678. doi:10.2147/ OPTH.S26753

101. Maa AY, Patel S, Chasan JE, Delaune W, Lynch MG. Retrospective evaluation of a teleretinal screening program in detecting multiple nondiabetic eye diseases. Telemed J e-Health. 2017;23(1):41-48. doi:10.1089/TMJ.2016.0039

102. Hanson C, Tennant MTS, Rudnisky CJ. Optometric referrals to retina specialists: evaluation and triage via teleophthalmology. Telemed J e-Health. 2008;14(5):441-445. doi:10.1089/TMJ.2007.0068

103. Helveston EM, Neely DE, Cherwek DH, Smallwood LM. Diagnosis and management of strabismus using telemedicine. Telemed $J$ e-Health. 2008;14(6):531-538. doi:10.1089/ TMJ.2007.0086

104. Cheung JC, Dick PT, Kraft SP, Yamada J, Macarthur C. Strabismus examination by telemedicine. Ophthalmology. 2000;107:1999-2005.

105. Dawson E, Kennedy C, Bentley C, Lee J, Murdoch L. The role of telemedicine in the assessment of strabismus. $J$ Telemed Telecare. 2002;8(1):52-55. doi:10.1258/1357633021937361

106. Murdoch I, Bainbridge J, Taylor P, Smith L, Burns J, Rendall J. Postoperative evaluation of patients following ophthalmic surgery. $J$ Telemed Telecare. 2000;6(SUPPL. 1):84-86. doi:10.1258/ 1357633001934258

107. CatTrax - innovation improves access to cataract surgery; 2021. Available from: https://www.cie.auckland.ac.nz/newsroom/cattraxinnovation-improves-access-to-cataract-surgery/. Accessed May 17, 2021.

108. Salcone EM, Johnston S, Vanderveen D. Review of the use of digital imaging in retinopathy of prematurity screening. Semin Ophthalmol. 2010;25(5-6):214-217. doi:10.3109/08820538.2010.523671

109. Kulathunga PASS, Kandasamy Y. Identification of risk factors and evaluation of digital funduscopic screening for retinopathy of prematurity in a regional neonatal unit in Australia. Sri Lanka J Child Health. 2010;39(3):98. doi:10.4038/sljch. v39i3.2272

110. Jackson KM, Scott KE, Graff Zivin J, et al. Cost-utility analysis of telemedicine and ophthalmoscopy for retinopathy of prematurity management. Arch Ophthalmol. 2008;126(4):493-499. doi:10.1001/archopht.126.4.493

111. Wilson CM, Cocker KD, Moseley MJ, et al. Computerized analysis of retinal vessel width and tortuosity in premature infants. Invest Ophthalmol Vis Sci. 2008;49(8):3577-3585. doi:10.1167/iovs.071353 
112. Murakami Y, Silva RA, Jain A, Lad EM, Gandhi J, Moshfeghi DM. Stanford University network for diagnosis of retinopathy of prematurity (SUNDROP): 24-month experience with telemedicine screening. Acta Ophthalmol. 2010;88(3):317-322. doi:10.1111/j.17553768.2009.01715.x

113. Ells AL, Holmes JM, Astle WF. Telemedicine approach to screening for severe retinopathy of prematurity: a pilot study. Ophthalmology. 2003;110(11):2113-2117. doi:10.1016/S01616420(03)00831-5

114. Wang SK, Callaway NF, Wallenstein MB, Henderson MT, Leng T, Moshfeghi DM. SUNDROP: six years of screening for retinopathy of prematurity with telemedicine. Can J Ophthalmol. 2015;50(2):101-106. doi:10.1016/J.JCJO.2014.11.005

115. Dai S, Chow K, Vincent A. Efficacy of wide-field digital retinal imaging for retinopathy of prematurity screening. Clin Experiment Ophthalmol. 2011;39(1):23-29. doi:10.1111/J.14429071.2010.02399.X

116. Murakami Y, Jain A, Silva RA, Lad EM, Gandhi J, Moshfeghi DM. Stanford University Network for Diagnosis of Retinopathy of Prematurity (SUNDROP): 12-month experience with telemedicine screening. $\mathrm{Br} J$ Ophthalmol. 2008;92 (11):1456-1460. doi:10.1136/BJO.2008.138867

117. Chiang MF. Interexpert agreement of plus disease diagnosis in retinopathy of prematurity. Archiv Ophthalmol. 2007;125 (7):875-880. doi:10.1001/ARCHOPHT.125.7.875

118. Chiang MF. Accuracy and reliability of remote retinopathy of prematurity diagnosis. Archiv Ophthalmol. 2006;124 (3):322-327. doi:10.1001/ARCHOPHT.124.3.322

119. Dhaliwal C, Wright E, Graham C, McIntosh N, Fleck BW. Widefield digital retinal imaging versus binocular indirect ophthalmoscopy for retinopathy of prematurity screening: a two-observer prospective, randomised comparison. Br J Ophthalmol. 2009;93 (3):355-359. doi:10.1136/BJO.2008.148908

120. Shah DN, Karp KA, Ying G-S, Mills MD, Quinn GE. Image analysis of posterior pole vessels identifies type 1 retinopathy of prematurity. $J$ AAPOS. 2009;13(5):507-508. doi:10.1016/J. JAAPOS.2009.07.004

121. Yen KG, Hess D, Burke B, Johnson RA, Feuer WT, Flynn JT. Telephotoscreening to detect retinopathy of prematurity: preliminary study of the optimum time to employ digital fundus camera imaging to detect ROP. J Am Assoc Pediatr Ophthalmol Strabismus. 2002;6 (2):64-70. doi:10.1067/MPA.2002.121616

122. Chiang MF. Telemedical retinopathy of prematurity diagnosis: accuracy, reliability, and image quality. Archiv Ophthalmol. 2007;125(11):1531-1538. doi:10.1001/ARCHOPHT.125.11.1531

123. Chalakkal RJ. Automatic retinal image analysis to triage retinal pathologies [Doctoral dissertation]. Auckland: University of Auckland; 2019. Available from: https://researchspace.auck land.ac.nz/handle/2292/49371.

124. Thanati H, Chalakkal RJ, Abdulla WH. On deep learning based algorithms for detection of diabetic retinopathy. In: ICEIC 2019 International Conference on Electronics, Information, and Communication; Institute of Electrical and Electronics Engineers Inc.; 2019. doi:10.23919/ELINFOCOM.2019.8706431.
125. Du XL, Li WB, Hu BJ. Application of artificial intelligence in ophthalmology. Int $J$ Ophthalmol. 2018;11(9):1555-1561. doi:10.18240/ijo.2018.09.21

126. Chalakkal RJ, Abdulla WH, Hong SC. Fundus retinal image analyses for screening and diagnosing diabetic retinopathy, macular edema, and glaucoma disorders. In: Diabetes and Fundus OCT. Elsevier; 2020:59-111. doi:10.1016/b978-0-12-8174401.00003-6

127. Burlina P, Pacheco KD, Joshi N, Freund DE, Bressler NM. Comparing humans and deep learning performance for grading AMD: a study in using universal deep features and transfer learning for automated AMD analysis. Comput Biol Med. 2017;82:80-86. doi:10.1016/j.compbiomed.2017.01.018

128. Gelman R, Jiang L, Du YE, Martinez-Perez ME, Flynn JT, Chiang MF. Plus disease in retinopathy of prematurity: pilot study of computer-based and expert diagnosis. $J$ AAPOS. 2007;11(6):532-540. doi:10.1016/J.JAAPOS.2007.09.005

129. Zhao R, Chen Z, Chi Z. Convolutional neural networks for branch retinal vein occlusion recognition? In: 2015 IEEE International Conference on Information and Automation, ICIA 2015 - In Conjunction with 2015 IEEE International Conference on Automation and Logistics; Institute of Electrical and Electronics Engineers Inc.; 2015: 1633-1636. doi:10.1109/ICInfA.2015.7279547.

130. Muhammad H, Fuchs TJ, De Cuir N. Hybrid deep learning on single wide-field optical coherence tomography scans accurately classifies glaucoma suspects. J Glaucoma. 2017;26 (12):1086-1094. doi:10.1097/IJG.0000000000000765

131. Hogarty DT, Mackey DA, Hewitt AW. Current state and future prospects of artificial intelligence in ophthalmology: a review. Clin Experiment Ophthalmol. 2019;47(1):128-139. doi:10.1111/ ceo. 13381

132. Bali S. Barriers to development of telemedicine in developing countries. In: Heston TF, editor. Telehealth. Intech Open; 2018. Available from: https://www.intechopen.com/chapters/64650. doi:10.5772/INTECHOPEN.81723

133. Ministry of Health. Briefing to the incoming Minister of Health. 2020.

134. de Ribot FM, de Ribot AM, Ogbuehi K, Large R. Teleophthalmology in the post-coronavirus era. $N Z \mathrm{Med} \mathrm{J}$. 2021;134(1538):139-143.

135. Xie L, Yang S, Squirrell D, Vaghefi E, Virgili G. Towards implementation of AI in New Zealand national diabetic screening program: cloud-based, robust, and bespoke. PLoS One. 2020;15 (4):e0225015. doi:10.1371/JOURNAL.PONE.0225015

136. Labiris G, Panagiotopoulou EK, Kozobolis VP. A systematic review of teleophthalmological studies in Europe. Int J Ophthalmol. 2018;11 (2):314-325. doi:10.18240/ijo.2018.02.22

137. Moher D, Liberati A, Tetzlaff J, Altman DG. PRISMA Group. Preferred reporting items for systematic reviews and meta-analyses: the PRISMA statement. Ann Intern Med. 2009;151(4):264269,W64. doi:10.7326/0003-4819-151-4-200908180-00135
Clinical Ophthalmology

\section{Publish your work in this journal}

Clinical Ophthalmology is an international, peer-reviewed journal covering all subspecialties within ophthalmology. Key topics include: Optometry; Visual science; Pharmacology and drug therapy in eye diseases; Basic Sciences; Primary and Secondary eye care; Patient Safety and Quality of Care Improvements. This journal is indexed on PubMed
Central and CAS, and is the official journal of The Society of Clinical Ophthalmology (SCO). The manuscript management system is completely online and includes a very quick and fair peer-review system, which is all easy to use. Visit http://www.dovepress.com/ testimonials.php to read real quotes from published authors. 